testes reflexológicos e atividade motora em campo aberto (locomoção, levantar, tempo de limpeza e defecação). Ratas Wistar prenhes foram divididas em 4 grupos experimentais, de acordo com a presença ou não de diabete e submetidas ou não ao estresse. O diabete foi induzido sete dias antes do acasalamento pela injeção intravenosa de estreptozotocina (40 mg/kg). O estresse por contenção foi aplicado, 1 hora/dia, durante o período organogênico $\left(6^{\circ}\right.$ ao $15^{\circ}$ dias de prenhez). O parto foi na- tural e seus filhotes foram acompanhados por 65 dias. A análise estatística dos dados revelou que o diabete reduziu o ganho de peso materno e prejudicou o desenvolvimento físico e comportamental da prole. O estresse por contenção em ratas diabéticas não potencializou as alterações causadas pelo diabete.

Palavras-Chave: Estresse. Diabete melito. Estudo experimental.

\title{
Anemia por Deficiência de Ferro e sua Absorção em Gestantes Adolescentes
}

Autor: Amélia Cirone Esposito Papa

Orientadores: Prof ${ }^{a}$ Dr $^{a}$ Rosiane Mattar e Prof.Dr. Luiz Camano

Tese apresentada ao Curso de Pós-graduação em Obstetrícia da Universidade Federal de São Paulo - Escola Paulista de Medicina, para obtenção do título de Doutor em Medicina, 30 de setembro de 2002.

Analisaram-se a prevalência de anemia, de ferropenia e a absorção aguda de ferro após suplementação oral em 56 gestantes adolescentes. Nosso objetivo foi avaliar a eficácia da hemoglobina na identificação da deficiência de ferro. A hemoglobina é o parâmetro rotineiramente empregado no Pré-Natal para avaliação de anemia ferropriva. Neste estudo foi introduzido um novo parâmetro para avaliação da ferropenia, conhecido como receptor de transferrina, considerado padrão-ouro, por não sofrer influência de fenômenos inflamatórios ou infecciosos. Os resultados obtidos foram comparados com a hemoglobina e com os demais parâmetros utilizados para avaliação da ferropenia: ferro sérico, ferritina, indice de saturação de transferrina e receptor de transferrina, para estudar a eficiência da hemoglobina na identificação da ferropenia.. Avaliou-se a absorção oral aguda pela de ferro comparando a dosagem desse elemento em jejum e após 2 horas da administração de $100 \mathrm{mg}$ de sulfato ferroso. A prevalência de anemia apurada pelo nivel de hemoglobina foi $21,4 \%$, sendo todas classificadas como anêmicas de grau leve. A ferritina [12 $\mu \mathrm{g} / \mathrm{dL}$ verificou deficiência de ferro em $21,4 \%$ das adolescentes, enquanto a ferritina [22 $\mu \mathrm{g} /$
dL reconheceu 37,5\% das gestantes como ferropênicas. Não se pôde valorizar a interpretação do receptor de transferrina, pela ausência de padronização internacional quanto à unidade de medida de dosagem e dificuldade de comparação dos diferentes kits encontrados no mercado. Quando se comparou a hemoglobina com os outros parâmetros como a ferritina, o ferro sérico, o índice de saturação de transferrina e o receptor de transferrina, encontrou-se que esses indices não avaliaram melhor que a hemoglobina, a deficiência de ferro. Concluiu-se que a dosagem de hemoglobina, em pacientes portadoras de anemia de grau leve, foi suficiente para avaliação da ferropenia. O melhor parâmetro para avaliação da ferropenia, baseado no teste de administração oral aguda de ferro, foi a ferritina $<22 \mu \mathrm{g} / \mathrm{dL}$, pois nesse grupo encontrou-se alta taxa de absorção, evidenciando que essas adolescentes tinham estoques de ferro insuficientes.

Palavras-chave: Anemia. Gravidez na adolescência. Absorção de ferro na gestação. Adolescência. Ferritina. Hemoglobina.

\section{Contribuição da Eletrocauterização Laparoscópica Ovariana Bilateral no Tratamento de Mulheres Inférteis com Sindrome dos Ovários Policísticos Clomifeno-resistentes}

Autor: Carlos Roberto Izzo

Orientador: Prof. Dr. Hans Wolfgang Halbe

Tese de Doutorado apresentada à Faculdade de Medicina da Universidade de São Paulo, em 22 de agosto de 2003

Foram estudadas prospectivamente 49 mulheres inférteis com síndrome dos ovários policísticos clomifeno-resistentes, separadas aleatoriamente em dois grupos. Vinte e quatro mulheres foram submetidas à eletrocauterização laparoscópica ovariana bilateral com corrente monopolar e as restantes, a até 
três ciclos de hiperestimulação ovariana controlada com hormônio foliculo-estimulante recombinante. Os objetivos do estudo foram: 1) avaliar os efeitos da eletrocauterização laparoscópica ovariana bilateral sobre o volume ovariano e as dosagens séricas do hormônio folículo-estimulante, hormônio luteinizante, testosterona, androstenediona e insulina; 2) determinar a associação entre as variáveis hormônio luteinizante > 12 UI, índice de massa corpórea, quociente glicemia de jejum / insulinemia de jejum e teste de tolerância à glicose oral e a taxa de gestação no grupo de mulheres submetidas à eletrocauterização laparoscópica ovariana bilateral e 3) comparar as taxas de gestação dos dois grupos de tratamento. Houve diminuição estatisticamente significativa do volume ovariano bilateral após a eletrocauterização laparoscópi- ca ovariana bilateral. Observou-se queda estatisticamente significativa dos níveis séricos de testosterona e androstenediona e uma tendência à queda na média dos niveis séricos de hormônio luteinizante. Não houve influência do nivel sérico de hormônio luteinizante, do indice de massa corpórea, do quociente glicemia/ insulina de jejum e do teste de tolerância à glicose oral na taxa de gestação após a eletrocauterização ovariana laparoscópica. A taxa de gestação obtida com a eletrocauterização ovariana laparoscópica, doze meses após o procedimento, não diferiu da taxa de gestação obtida com três ciclos de indução ovulatória com hormônio folículo-estimulante recombinante.

Palavras-chave: Síndrome dos ovários policísticos. Eletrocauterização ovariana laparoscópica. Anovulação.

\section{Estudo da Prevalência e dos Fatores Associados às Lesōes Intra-epiteliais Escamosas do Colo Uterino em Mulheres Infectadas pelo HIV}

Autor: Ricardo José de Oliveira e Silva

Orientador: Prof. Dr. Aldo Franklin Ferreira Reis

Tese de Doutorado apresentada ao Programa de Pós-graduação em Clínica Médica, Setor de Pesquisa Clínica, da Universidade Federal do Rio de Janeiro - UFRJ, em 12 de maio de 2003.

Objetivos: Avaliar a prevalência de lesões escamosas intra-epiteliais cervicais em pacientes infectadas pelo HIV atendidas em rede pública na Cidade do Rio de Janeiro e estudar os fatores associados a essas lesões. Material e Método: 354 pacientes infectadas pelo HIV e atendidas em serviços públicos na Cidade do Rio de Janeiro foram submetidas a exame ginecológico, colheita de citologia e exame colposcópico do colo uterino e vulva. A associação do diagnóstico de lesão intra-epitelial do colo foi analisada de acordo com os resultados de variáveis clínicas (idade e presença de lesões vulvares), laboratoriais (contagem de CD4) e comportamentais (número de parceiros e hábito de fumar).

Resultados: A prevalência de lesões intra-epiteliais do colo uterino foi de $35,5 \%$. Na análise multivariada mostraram-se significativas: contagem de CD4 abaixo de 350 céls $/ \mathrm{mm}^{3} \mathrm{OR}=2,31$ [IC 95\% 1,43 - 3,75], hábito de fumar OR = 1,83 [IC 95\% 1,13 - 2,97], a lesão intra- epitelial vulvar OR = 2,28 [IC 95\% 1,41 - 3,70] e a idade abaixo de 33 anos OR = 1,74 [IC 95\% 1,07 - 2,82]. Na análise do subgrupo das lesões de alto grau mostraram-se significativas: contagem de CD4 abaixo de 350 céls $/ \mathrm{mm}^{3}$ OR = 2,62 [IC 95\% 1,13 - 6,10], hábito de fumar OR = 2,72 [IC 95\% 1,20 - 6,21] e idade abaixo de 33 anos OR = 2,56 [IC 95\% 1,10 - 5,96].

Conclusões: É alta a prevalência de lesões intraepiteliais do colo uterino em pacientes infectadas pelo HIV. A imunodeficiência, o hábito de fumar, a presença de lesões intra-epiteliais na vulva e a idade abaixo de 33 anos estão associadas à presença de lesões intraepiteliais do colo uterino. Excetuando-se as lesões vulvares, a mesma associação foi encontrada para as lesões intra-epiteliais de alto grau.

Palavras-chave: AIDS. Colo: lesões pré-neoplásicas. Tabagismo. Epidemiologia. 